\title{
Statistical Analysis of Stone Mastic Asphalt Incorporating Kenaf Fiber
}

\author{
G. Danoshini', A. Baqadeem¹ A. K. S. Al-Shakhrit1', N. E. Jasni1 and K. A. Masri1,2* \\ ${ }^{1}$ College of Engineering, Universiti Malaysia Pahang, Lebuhraya Tun Razak, 26300, Gambang, Kuantan, Pahang, Malaysia \\ ${ }^{2}$ Earth Resources and Sustainability Centre (ERAS), Universiti Malaysia Pahang, 26300 Gambang, Pahang, Malaysia
}

ABSTRACT - Stone mastic asphalt consists of two components of coarse aggregate and bitumenfilled mortar (bituminous blend, filler and stabilizing additives like cellulosic or mineral fibers). Such form of hot mix asphalt (HMA) was first developed in Germany in the mid-1960s to cope with corrosion and ribbed wheel destruction. The mixture was then known as stone mastic asphalt (SMA), which was not only immune to ribbed wheels but also has strong resistance against rutting. One of the most significant problem when constructing the stone mastic asphalt pavement is permanent deformation. By through the load of traffic and the strain of the tyres, much of the irreversible deformation happens in the ground. According to previous study, researchers have stated that the kenaf fibre's physical strength and thermal characteristics are superior compared to other forms of natural fiber polymer composites, and therefore deemed a desirable applicant for elevated-performance natural fiber composite materials. Thus, the aim of this study is to assess the mechanical performance of stone mastic asphalt incorporating kenaf fibre by developing a regression model. A set of data of SMA mixture incorporating various percentages of kenaf fibre were assessed through statistical analysis in Minitab 19 by using the resilient modulus as the dependant variable in the first model and the accumulated strain from the dynamic creep test as the dependant variable in the second model. The regression models showed a positive impact of kenaf fibre as an addictive in the SMA mixture. For more future studies, it is recommended to analyse the effect of various proportion of kenaf fibre with bitumen modification towards stone mastic asphalt performance that will render the satisfactory performance of SMA during service.
ARTICLE HISTORY

Received: $17^{\text {th }}$ March 2021

Revised: $7^{\text {th }}$ April 2021

Accepted: $21^{\text {st }}$ April 2021

\section{KEYWORDS}

Stone Mastic Asphalt;

Kenaf Fibre;

Additive;

Resilient Modulus;

Statistical Analysis

\section{INTRODUCTION}

Some additives may induce some difference in one or more of the following situations by encouraging the characteristics of bitumen or bitumen mortar used for the stone mastic asphalt [1]. The roadways have endured losses such as cracking and rutting over their lifetimes. The engineers are trying to enhance the functional characteristics and characteristics of hot mixes of asphalt with the additives because of increasing traffic loads [2]. Built-up strain in or around the asphalt layer is one of the main deteriorations in high-temperature asphalt mixes. Asphalt mastic has a structure with a degree of gap and a higher binding content than hot asphalt mix, which indicates that the use of additives to modify binders has an important role in improving mixture efficiency. Besides, the usage of fabrics or polymers will eventually arise due to large concentrations of bitumen $[3,8,9]$.

This research uses kenaf fiber to improve the performance of stone mastic asphalt. Kenaf is considered one of the biggest local fibers widely used in various sectors due to the multi-use of its cellulose fibers mentioned by other researchers that use kenaf fiber in their study. The scientific name is Hibiscus Cannabinus, and it is one of the wellgrowing non-wood lignocelluloses in tropical and subtropical areas. It is worth exploring the usage of Kenaf fiber in SMA mixture as the availability of Kenaf supplies in Malaysia would result in lower SMA pavements development costs. Therefore, it can also be appraised as an environmentally friendly material that promotes sustainability in pavements. Kenaf fiber may also be an acceptable source for substituting synthetic fiber for the SMA14 mixture [4, 11, 12].

Kenaf bast fiber has outstanding tensile strength and excellent flexural strength confirmed by few mechanical tests and work, enabling it to be used in a wide range of industries [5, 13, 14]. Therefore, in this study, kenaf fiber as a natural fiber enhances stone mastic asphalt engineering properties.

Another study has mentioned that a popular approach to the behavior of asphalt mixtures is to use additives such as polymers, including fibers in bitumen and asphalt studies, and nanomaterials to enhance the behavior of bitumen and pavement mixtures have in recent years been used by researchers $[2,6,7,10]$.

This research study is aimed to develop a regression model to evaluate the mechanical performances of stone mastic asphalt incorporating kenaf fiber. Minitab 19 is used for this research. 


\section{METHODOLOGY}

\section{Model Development}

Minitab 19 was used to develop a regression model of stone mastic asphalt incorporating kenaf fiber. There were two models developed in this project. The first model is the resillient modulus related to the temperature, percentage of kenaf fiber incorporated, the number of revolutions from abrasion loss test, and accumulated strain from the dynamic creep test. The second model is the accumulated strain related to the temperature, percentage of kenaf fiber, and the number of revolutions from abrasion loss. There were also two trials made under each of these models. The second trial of both models had dismissed the parameter, which does not affect the dependant variable. The overall process of developing these models included descriptive statistics, correlation analysis, multiple linear regression model, normality test, and the paired t-test.

The first model relates the resilient modulus to the temperature of the test, which was at either 25 degrees and 40 degrees, percentage of kenaf fiber which was in the range of $0,0.2,0.3,0.4,0.5$, and 0.6 , the number of revolutions from the abrasion loss and the accumulated strain from the dynamic creep test. There were two trials made under the first model to notice the difference it would make to dismiss the parameters that do not affect the results in the first trial of model one. The second trial was made by dismissing the accumulated strain as it does not affect the dependant variable, which is the resilient modulus.

The second model was initiated by accumulated strain as the dependant variable. In contrast, the test temperature, which was at 25 degrees and 40 degrees, percentage of kenaf fiber at ranges of $0,0.2,0.3,0.4,0.5,0.6$, and the number of revolutions from the abrasion loss test were made as to the independent variable. There were also two trials made under this model. The second trial of the second model was made by dismissing the temperature of the test as it did not affect the dependant variable, accumulated strain in the earlier trial of the second model.

\section{Correlation Analysis}

Analysis to produce a regression model was performed by using Minitab 19. From Minitab 19, descriptive statistics describe the basic features of the data in this study, correlation analysis between two quantitative variables to evaluate the strength and linear regression model for developing a model from the prediction of numerical value. On the other hand, analysis of variance, the p-value helps conclude the null hypothesis based on the other variables' value. The normality test is used to determine whether the sample data has been drawn from a normally distributed population. In contrast, a t-test is used to determine the difference of significant population mean.

\section{RESULTS AND DISCUSSION}

\section{Descriptive Analysis of Resilient Modulus Parameter}

The Resilient Modulus data after screening are tabulated below. Figure 1 shows the descriptive statistics data of model 1, whereas Figure 2 shows model 2.

\section{Statistics}

\begin{tabular}{lrrrrrrrr} 
Variable & Mean StDev Variance & Minimum Median Maximum Skewness Kurtosis \\
\hline resilient modulus & 1619 & 1068 & 1139769 & 315 & 1007 & 4083 & 0.71 & -0.71 \\
temperature & 32.50 & 7.61 & 57.86 & 25.00 & 32.50 & 40.00 & 0.00 & -2.12 \\
$\%$ of kenaf fibre & 0.3333 & 0.2000 & 0.0400 & 0.0000 & 0.3500 & 0.6000 & -0.35 & -0.92 \\
number of revolution & 1.1300 & 0.5010 & 0.2510 & 0.4700 & 1.1050 & 2.1500 & 0.21 & -0.94
\end{tabular}

Figure 1. Descriptive statistics of Model 1

\section{Statistics}

\begin{tabular}{|c|c|c|c|c|c|c|c|}
\hline Variable & Mean StDev & riance $\mathrm{N}$ & nimum $\mathrm{N}$ & Median I & ximum $S$ & wness & irtosis \\
\hline accumulated strain & $9288 \quad 6240$ & 3932411 & 1947 & 9492 & 15631 & -0.03 & -2.07 \\
\hline$\%$ of kenaf fibre & 0.33330 .2000 & 0.0400 & 0.0000 & 0.3500 & 0.6000 & -0.35 & -0.92 \\
\hline number of revolution & 1.13000 .5010 & 0.2510 & 0.4700 & 1.1050 & 2.1500 & 0.21 & -0.94 \\
\hline
\end{tabular}

Figure 2. Descriptive statistics of Model 2 


\section{Correlation analysis of Resilient Modulus Parameter}

Correlation analysis is the procedure applied to identify the possible relationship between the dependent and independent variables. Later will be used to develop regression models. Each column denotes both Pearson Correlation value and p-value, where Pearson Correlation value is presented as top row, meanwhile p-value presented at the bottom row. Table 1 shows the correlation matrix among variables of model 1, whereas table 2 indicates the correlation matrix among variables of model 2 .

Table 1. Correlation Matrix of Model 1

\begin{tabular}{cccc}
\hline & Resilient modulus & Temperature & $\%$ of Kenaf Fibre \\
\hline Temperature & -0.816 & & \\
\hline$\%$ of kenaf fibre & 0.215 & 0.0 & 0.177 \\
\hline Number of revolution & -0.109 & 0.0 & 0.0 \\
\hline
\end{tabular}

Table 2. Correlation Matrix of Model 2

\begin{tabular}{ccc}
\hline & Accumulated strain & Number of revolutions \\
\hline Number of revolutions & 0.127 & \\
\hline$\%$ of Kenaf Fibre & 0.18 & 0.2 \\
\hline
\end{tabular}

\section{Linear Regression Model of Resilient Modulus Parameter}

The first linear regressions model was carried out with the resilient modulus of stone mastic asphalt mixture as the response. Simultaneously, temperature, percentage of kenaf fiber, and several revolutions were the predictors. Meanwhile, the second model lists accumulated strain as the response and percentage of kenaf fiber and number of revolutions as the predictors. The equations shown below showed that the coefficient for all important variables for this model had a positive sign implying that an increment of all independent variables would lead to an increment value of the dependant variables.

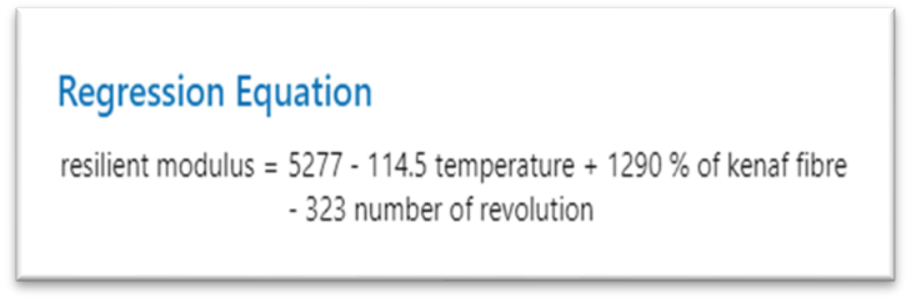

Figure 3. Regression Equation of Model 1

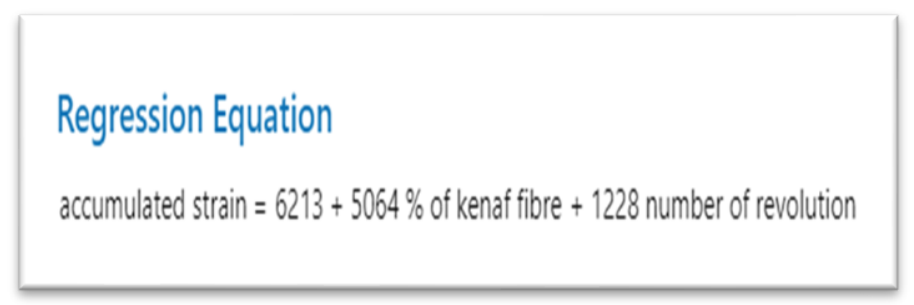

Figure 4. Regression Equation of Model 2

Besides, R-sq is one of the criteria used to determine whether a linear relationship between the response and the predictor fits the data well. The R-sq for model 1 after dismissing accumulated strain was $73.46 \%$ through the model summary, whereas for model 2 after dismissing temperature, R-sq was $4.17 \%$, which is far from a hundred percent. Therefore, the linear relationship between the response and the predictor of model 2 doesn't fit the data well. As shown in the analysis of variance, described that certain variables for the Resilient modulus model were significant independent variables for predicting Resilient modulus where the $p$-value of the linear regression was less than 0.05 ( $p$-value $<0.05$ ), which means the null hypothesis (H0) was rejected. The alternative hypothesis (H1) was accepted. Unfortunately, the pvalue for model 2 was above 0.05 , and the predictor cannot be used for predicting. The hypothesis for the final model for estimating this model can be stated as follows; 
$\mathrm{H}_{0}=$ the predictor cannot be used for predicting in the model.

$\mathrm{H}_{1}=$ the predictor can be used for predicting in the model.

\section{Analysis of Variance}

The variance (ANOVA) portion of the output is as shown in Figure 5 and Figure 6, respectively. From Figure 5, the $\mathrm{p}$-value is less than the $\alpha$-level of 0.05 . Hence, the regression model was significant and could explain or predict the resilient modulus if the empirical data of selected independent variables were used. Still, Figure 6 shows the p-value, which is more than the $\alpha$-level of 0.05 , so the regression model is not significant and thus could not be used to explain or predict the accumulated strain.

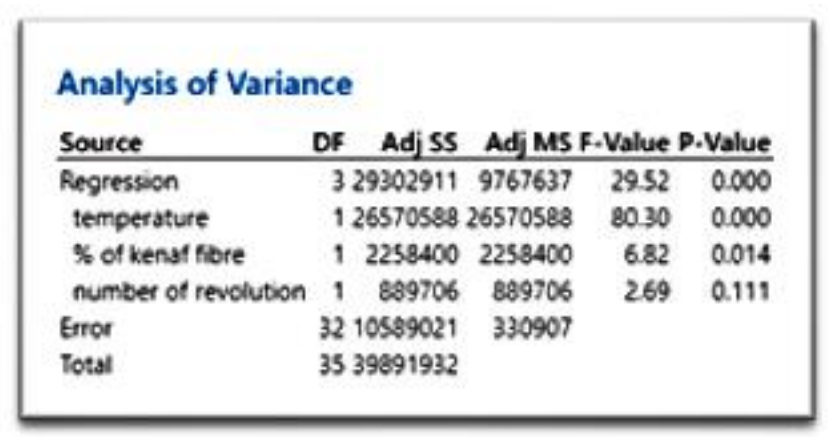

Figure 5. ANOVA of Model 1

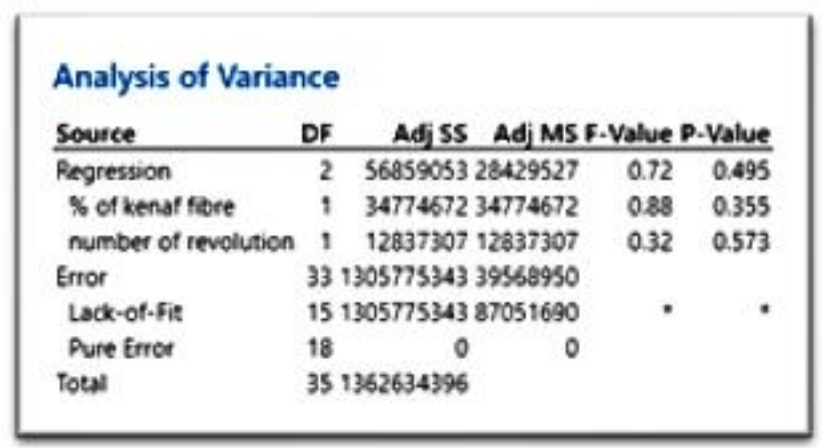

Figure 6. ANOVA of Model 2

\section{Normality Test}

The skewness value for the resilient modulus model is -1.24 , while the Kurtosis value is 2.63 , which is close to 0 , which means the data can be accepted for model development. The skewness value for the accumulated strain model is 0.11. The Kurtosis value is -1.88 , which is close to 0 , which means the data can be accepted for model development but has to be altered due to the inability to produce a successful linear regression model. Other than that, Normality Test is also evaluated using the Kolmogorov-Smirnov (KS) test, where the P-value should be more than 0.050 to indicate the normality of the developed model. In model 1 , the p-value was more than 0.050 as it was at 0.118 and eventually passed the requirement, and later on in model 2 , after the data transformation process, the p-value was still at 0.118 , and no changes were to be seen. Figure 7 shows the probability plot for residual, which was the same before and after data transformation. 


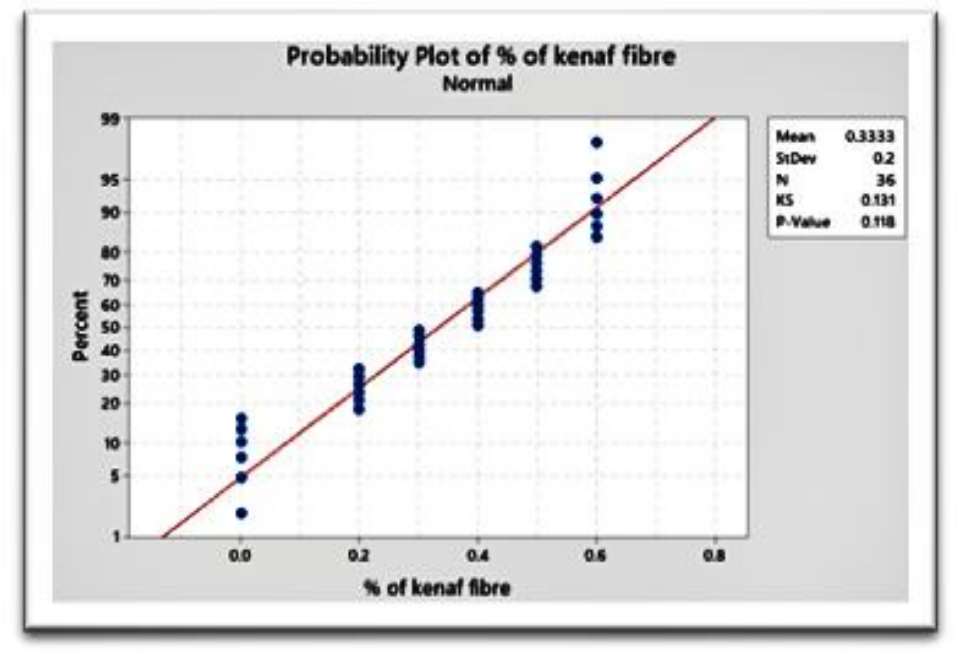

Figure 7. Probability Plot for both Models

\section{Paired T-Test}

Figure 8 and Figure 9 show that the p-value is lesser than 0.05, which means sufficient evidence to reject the H0. Therefore, the null hypothesis (H0) is rejected at the 5\% level of significance. This indicates that the resilient modulus predicted model differs much from the resilient modulus empirical values. The accumulated strain predicted model differs much from the accumulated strain empirical values, respectively.

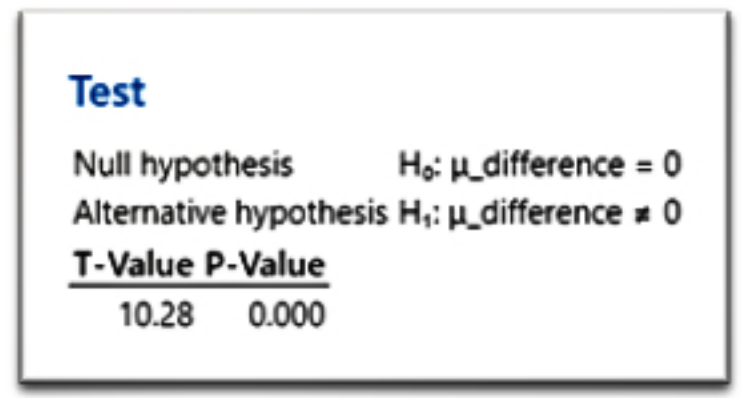

Figure 8. Validation analysis of Model 1

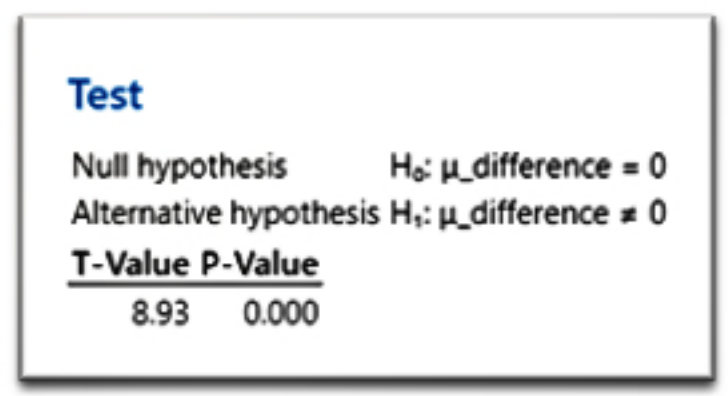

Figure 9. Validation analysis of Model 2

\section{CONCLUSION}

This study statistically investigated the performance of stone mastic asphalt incorporating kenaf fiber with different percentages of fiber content and developed a successful regression model. Based on the results, the following conclusions can be drawn;

a) A successful regression model of stone mastic asphalt incorporating kenaf fiber was developed.

b) The regression equations showed that the coefficient for all important variables for this model had a positive sign implying that an increment of all independent variables would lead to an increment value of both models. 


\section{ACKNOWLEDGEMENT}

The authors would like to thank UMP for funding this work under an internal grant, PDU203206.

\section{References}

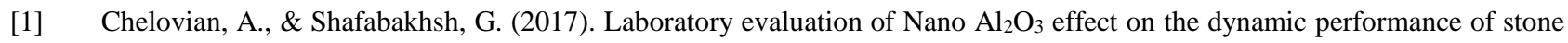
mastic asphalt. International Journal of Pavement Research and Technology, 10(2), 131-138.

[2] Kordi, Z., \& Shafabakhsh, G. (2017). Evaluating mechanical properties of stone mastic asphalt modified with $\mathrm{Nano} \mathrm{Fe}_{2} \mathrm{O}_{3}$. Construction and Building Materials, 134, 530-539.

[3] Ameli, A., Babagoli, R., Khabooshani, M., Aliasgari, R., \& Jalali, F. (2020). Permanent deformation performance of binders and stone mastic asphalt mixtures modified by SBS/montmorillonite nanocomposite. Construction and Building Materials, $239,117700$.

[4] Arshad, A. K., Mansor, S., Shafie, E., \& Hashim, W. (2016). Performance Of Stone Mastic Asphalt Mix Using Selected Fibres. Jurnal Teknologi, 78(7-2).

[5] Nur Syafiqah, S. M. Z., K. A. Masri, N. E. Jasni \& M. Hasan (2021). Performance of Stone Mastic Asphalt incorporating Kenaf Fiber. IOP Conf Series: Earth and Environmental Science, 641, 012001.

[6] Ameri, M., Mohammadi, R., Vamegh, M., \& Molayem, M. (2017). Evaluation of the effects of nanoclay on permanent deformation behavior of stone mastic asphalt mixtures. Construction and Building Materials, 156, 107-113.

[7] Katman, H. Y., Ibrahim, M. R., Karim, M. R., Mashaan, N. S., \& Koting, S. (2015). Evaluation of Permanent Deformation of Unmodified and Rubber-Reinforced SMA Asphalt Mixtures Using Dynamic Creep Test. Advances in Materials Science and Engineering, 2015, 1-11.

[8] Luo, Y., Zhang, K., Li, P., Yang, J., \& Xie, X. (2019). Performance evaluation of stone mastic asphalt mixture with different high viscosity modified asphalt-based on laboratory tests. Construction and Building Materials, 225, 214-222.

[9] Yadykina, V., Tobolenko, S., Trautvain, A., \& Zhukova, A. (2015). The Influence of Stabilizing Additives on Physical and Mechanical Properties of Stone Mastic Asphalt Concrete. Procedia Engineering, 117, 376-381.

[10] Masri, K. A., H. Awang, R. P Jaya, A. K. Arshad, "Moisture susceptibility of porous asphalt mixture with nano-silica modified asphalt binder," IOP Conference Series: Earth and Environmental Science, 224(1), 012028, 2019.

[11] Arshad, A. K., M. S. Samsudin, K. A. Masri, M. R. Karim, A. G. Abdul Halim, "Multiple stress creep and recovery of nanosilica modified asphalt binder," MATEC Web of Conference, 103, 09005, 2017.

[12] Arshad, A. K., K. A. Masri, \& Ahmad, J. "Investigation on Moisture Susceptibility and Rutting Resistance of Asphalt Mixtures incorporating Nanosilica Modified Binder," Pertanika Journal of Science and Technology, 25, 19-30, 2017.

[13] Arshad, A. K., E. Shaffie, W. Hashim, F. Ismail, and K. A. Masri, "Evaluation of nanosilica modified stone mastic asphalt," Int. J. Civ. Eng. Technol., vol. 10, no. 2, pp. 1508-1516, 2019.

[14] Arshad, A. K., J. Ahmad, K. A. Masri "Rutting resistance of nanosilica modified porous asphalt," Int. J. Civ. Eng. Technol., vol. 10, no. 1, pp. 2274-2284, 2019 